\title{
Electroporation enhances the ability of lactobacilli to remove cholesterol
}

\author{
H. S. Lye, A. A. Karim, G. Rusul, and M. T. Liong ${ }^{1}$ \\ School of Industrial Technology, Universiti Sains Malaysia, 11800 USM Penang, Malaysia
}

\begin{abstract}
The objective of the present study was to evaluate the effect of electroporation on the membrane properties of lactobacilli and their ability to remove cholesterol in vitro. The growth of lactobacilli cells treated at $7.5 \mathrm{kV} / \mathrm{cm}$ for $4 \mathrm{~ms}$ was increased by 0.89 to $1.96 \log _{10} \mathrm{cfu} / \mathrm{mL}$ upon fermentation at $37^{\circ} \mathrm{C}$ for 20 $\mathrm{h}$, the increase being attributed to the reversible and transient formation of pores and defragmentation of clumped cells. In addition, an increase of cholesterol assimilation as high as $127.2 \%$ was observed for most cells electroporated at a field strength of $7.5 \mathrm{kV} / \mathrm{cm}$ for $3.5 \mathrm{~ms}$ compared with a lower field strength of $2.5 \mathrm{kV} /$ $\mathrm{cm}$. Electroporation also increased the incorporation of cholesterol into the cellular membrane, as shown by an increased cholesterol:phospholipids ratio (50.0-59.6\%) upon treatment at $7.5 \mathrm{kV} / \mathrm{cm}$ compared with treatment at $2.5 \mathrm{kV} / \mathrm{cm}$. Saturation of cholesterol was observed in different regions of the membrane bilayer such as upper phospholipids, apolar tail, and polar heads, as indicated by fluorescence anisotropy using 3 fluorescent probes. Electroporation could be a useful technique to increase the ability of lactobacilli to remove cholesterol for possible use as cholesterol-lowering adjuncts in the future.
\end{abstract}

Key words: electroporation, cholesterol, Lactobacillus, incorporation

\section{INTRODUCTION}

A high level of cholesterol in the blood has been associated with increased risk of cardiovascular diseases such as coronary heart disease and stroke. Cardiovascular disease is one of the most common diseases found in developing countries and better management of it is urgently required because of the increased occurrence annually (Ooi et al., 2010). Studies have shown that an increase in cholesterol level of $1 \mathrm{mmol}$ could elevate the risk of coronary heart disease by $35 \%$ and the risk of coronary death by $45 \%$ (Liong and Shah, 2005). Vari-

Received April 7, 2011.

Accepted June 5, 2011.

${ }^{1}$ Corresponding author: mintze.liong@usm.my ous dietary means have been implemented to reduce blood cholesterol levels, such as the reduced intake of high-cholesterol foods, increased intake of fiber, and drug intervention. Recent studies have found that consumption of lactobacilli could reduce blood cholesterol levels and improve blood lipoprotein profiles (Liong, 2007; Ooi et al., 2010).

Lactobacilli are generally characterized as grampositive, non-spore-forming, nonflagellated rods or coccobacilli (Gomes and Malcata, 1999). They are among the most common probiotic microorganisms typically associated with the human gastrointestinal tract (Holzapfel et al., 2001). Probiotics are live microorganisms that confer a health benefit on the host when consumed in adequate amounts (Lye et al., 2009). Ziarno (2008) reported that Lactobacillus acidophilus had various abilities to take up cholesterol from different media, such as de Man, Rogosa, and Sharpe broth and artificial gastrointestinal fluids. In our previous studies (Lye et al., 2010a,b), we found that lactobacilli remove cholesterol mainly via assimilation of cholesterol during growth and incorporation of cholesterol into the cellular membrane. We have also reported that the incorporated cholesterol was mainly saturated in the regions of hydrophobic tails, upper phospholipids, and hydrophilic heads of the cellular membrane bilayer.

Electroporation or electropermeabilization is induced by an externally applied electric field and is a wellrecognized physical process in biological cells that influences permeability and diffusion across membranes of bacterial cells. The electric field applied to the cell membrane leads to the formation of pores in the cell membrane (Shil et al., 2008). Thus, cell membranes become permeabilized to ions and molecules when an intensity greater than a given critical threshold value is reached, and this value is specific to individual cells. The electropermeabilization process can be reversible and most of the cells return to their normal physiological state with the use of suitable pulse parameters (Tryfona and Bustard, 2008). Puc et al. (2003) reported that, following treatment, cells were able to transport molecules across the membrane via diffusion, electrophoresis, and electro-osmosis, indicating that electroporation could alter the membranes of bacterial cells. We postulate that such a membrane alteration 
could increase the incorporation of cholesterol into the cellular membrane. To our knowledge, no published study has reported on the use of such a treatment to enhance the ability of lactobacilli to remove cholesterol.

Thus, the objectives of this study were to evaluate the effect of electroporation on cell growth, cholesterol removal, and membrane properties of lactobacilli. The membrane properties evaluated included membrane permeability, lipid peroxidation, and ratio of cellular cholesterol:phospholipids (C:P). The effect of electroporation on the saturation of cholesterol within the cellular membrane was also determined.

\section{MATERIALS AND METHODS}

\section{Bacterial Cultures}

Pure cultures of Lactobacillus acidophilus BT 1088, L. acidophilus FTCC 0291, Lactobacillus bulgaricus FTCC 0411, L. bulgaricus FTDC 1311, and Lactobacillus casei BT 1268 were obtained from the Culture Collection Center of Universiti Sains Malaysia (Penang, Malaysia). Each stock culture was stored at $-20^{\circ} \mathrm{C}$ in $40 \%$ (vol/ vol) sterile glycerol. All lactobacilli were subcultured 3 times in sterile de Man, Rogosa, and Sharpe (MRS) broth (Hi-Media, Mumbai, India) supplemented with $0.15 \%$ (wt/vol) L-cysteine.HCl (Hi-Media) before experimental use.

\section{Sample Preparation}

Activated cells were harvested by centrifugation at $12,000 \times g$ for 15 min at $4^{\circ} \mathrm{C}$ (B. Braun, Melsungen, Germany). The cell pellet was washed twice with $1 \mathrm{mM}$ sucrose (R\&M, Essex, UK) and then resuspended in the same sucrose solution. Sterile sucrose $(1 \mathrm{~m} M)$ with $10 \%$ (vol/vol) washed lactobacilli cells was then electroporated (MicroPulser, Bio-Rad Laboratories, Hercules, $\mathrm{CA}$ ) at a capacitance of $25 \mu \mathrm{F}$, resistance of $200 \Omega$, and constant cooling at $4^{\circ} \mathrm{C}$. The field strength was adjusted to $2.5,5.0$, or $7.5 \mathrm{kV} / \mathrm{cm}$ with exposure times of $3,3.5$, or $4 \mathrm{~ms}$. Untreated cells were used as a control.

\section{Growth}

The growth of treated cells after fermentation at $37^{\circ} \mathrm{C}$ for $20 \mathrm{~h}$ was determined using the pour-plate method. Briefly, MRS agar supplemented with $0.15 \%$ (vol/vol) L-cysteine $\cdot \mathrm{HCl}$ (Hi-Media) was used for plating, and duplicates plates were incubated at $37^{\circ} \mathrm{C}$ for $48 \mathrm{~h}$.

\section{Assimilation of Cholesterol}

Sterile MRS broth containing $100 \mu \mathrm{g} / \mathrm{mL}$ of cholesterol (Hi-Media), $0.15 \%$ (wt/vol) L-cysteine. $\mathrm{HCl}$ (Hi-
Media), 0.3\% (wt/vol) oxgall (Sigma-Aldrich, St. Louis, $\mathrm{MO}$ ), and $0.1 \%$ (wt/vol) pancreatin (Sigma-Aldrich) was inoculated with treated and untreated (control) cells. The resulting mixture was adjusted to $\mathrm{pH} 8.0$ to mimic the condition of the human small intestine and incubated at $37^{\circ} \mathrm{C}$ for $20 \mathrm{~h}$. After the incubation period, the mixture was centrifuged at $12,000 \times g$ at $4^{\circ} \mathrm{C}$ for $15 \mathrm{~min}$. The supernatant and cells were collected separately for the determination of cholesterol assimilation as described previously (Lye et al., 2010a).

\section{Determination of Permeabilized Cells}

The determination of permeabilized cells was performed according to the method of Tryfona and Bustard (2008). Briefly, treated and untreated (control) cells were dyed with fluorescing propidium iodide before reading using a fluorescence spectrophotometer (Cary Eclipse, Palo Alto, CA) with excitation and emission wavelengths set at $538 \mathrm{~nm}$ and $617 \mathrm{~nm}$, respectively. A positive control with completely permeabilized membrane was prepared by treating the cells with $1 \%$ (vol/ vol) SDS for $10 \mathrm{~min}$. The percentage of permeabilized cells was then calculated as

$$
\text { Permeabilized cells }(\%)=(\mathrm{A}-\mathrm{B}) / \mathrm{C} \times 100 \% \text {, }
$$

where $\mathrm{A}$ is the fluorescence emission of cells immediately after treatment, $\mathrm{B}$ is the fluorescence emission of untreated cells, and $\mathrm{C}$ is fluorescence emission of all cells with broken membranes.

\section{Lipid Peroxidation}

The lipid peroxidation of lactobacilli cells was evaluated according to the method of GiamarellosBourboulis et al. (2003), based on the determination of malondialdehyde released using the thiobarbiturate assay. Briefly, treated and untreated (control) cells were reacted with trichloroacetic acid before treatment with thiobarbituric acid. The concentration of malondialdehyde was determined spectrometrically at $535 \mathrm{~nm}$ based on a standard curve created with 1,1,3,3-tetramethoxypropane (Merck, Darmstadt, Germany).

\section{Incorporation of Cholesterol into Cellular Membranes}

Two milliliters of cell suspension [optical density at $600 \mathrm{~nm}$ of 0.3 ] with glass beads $(2 \mathrm{~g} ; 0.43-0.60 \mathrm{~mm}$; Sigma-Aldrich) was vortexed for 2 min and placed in an ice bath for $1 \mathrm{~min}$. This step was repeated 5 times. Intracellular contents and cellular membranes were separated via centrifugation $\left(12,000 \times g, 4^{\circ} \mathrm{C}, 15 \mathrm{~min}\right)$, 
Table 1. Growth $\left(\log _{10} \mathrm{cfu} / \mathrm{mL}\right)$ of control and electroporated cells after fermentation at $37^{\circ} \mathrm{C}$ for $20 \mathrm{~h}$ and treatment for $3,3.5$, or 4 ms at field strength of $2.5,5.0$, or $7.5 \mathrm{kV} / \mathrm{cm}^{1}$

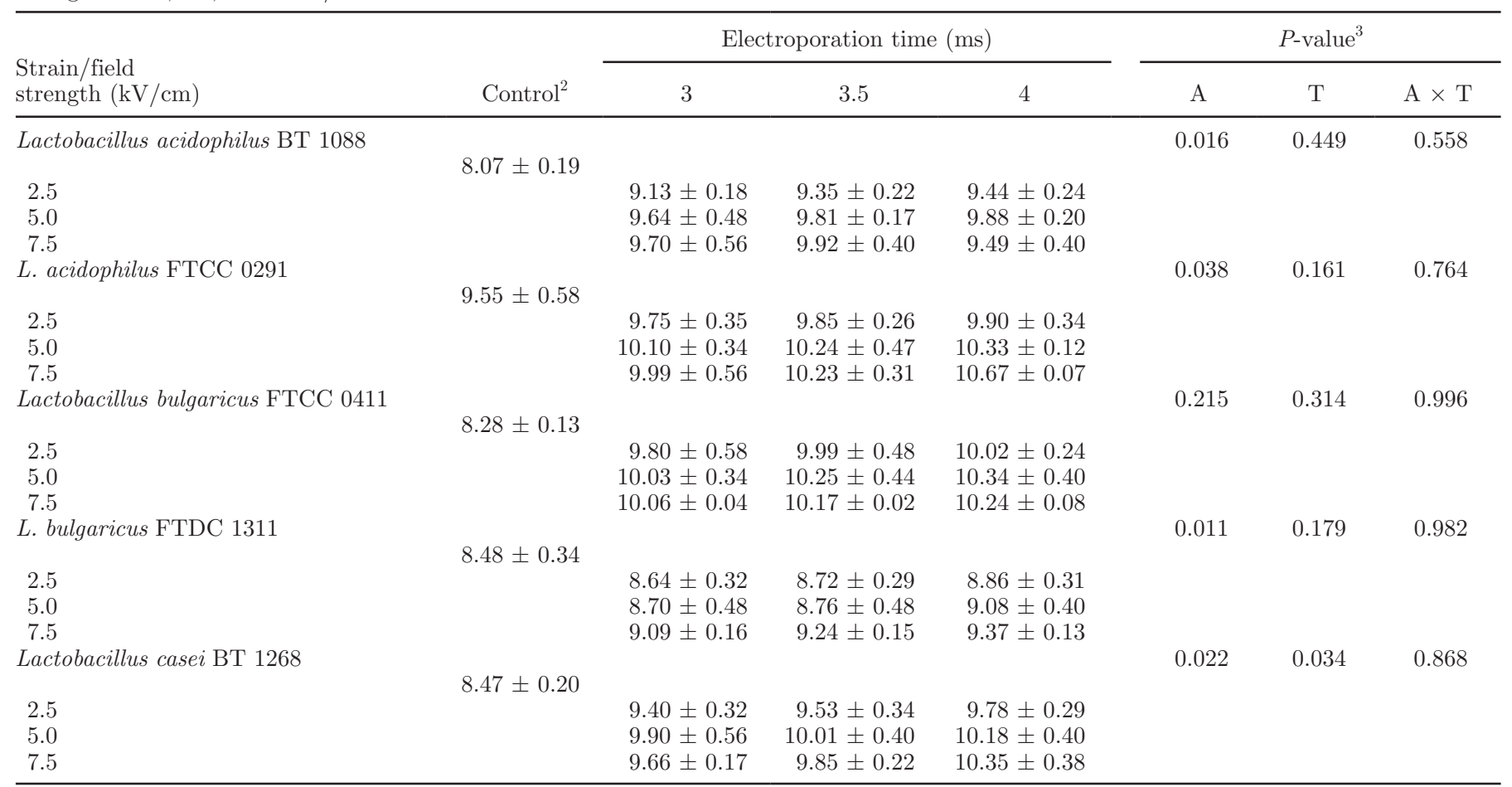

${ }^{1}$ Results are expressed as means \pm SD of means; values are means of duplicates from 3 separate runs $(n=3)$.

${ }^{2}$ Control $=$ sample without electroporation treatment.

${ }^{3} \mathrm{~A}=$ effect of electric field strength; $\mathrm{T}=$ effect of treatment duration; $\mathrm{A} \times \mathrm{T}=$ interaction between electric field strength and treatment duration.

and the cellular membrane was collected for subsequent analyses. Incorporation of cholesterol into cellular membranes was examined based on the determination of membrane cholesterol and phospholipid contents, and on the fluidity properties of the membrane via insertion of fluorescence probes.

The concentration of membrane cholesterol and phospholipids from treated and untreated (control) cells were extracted according to the method of Liong and Shah (2005). The extracted portions were examined for total cholesterol and phospholipid contents using commercial enzymatic kits (bioMerieux Corp., Marcy l'Etoile, France). The fluorescence anisotropies (FAn) of membrane from treated cells was determined using 3 fluorescent probes; namely 1,6-diphenyl-1,3,5-hexatriene (DPH; Sigma-Aldrich), 1-(4-trimethylammonium)6-phenyl-1,3,5-hexatriene (TMA-DPH; Sigma-Aldrich), and 8-anilino-1-napthalenesulfonic acid (ANS; Sigma-Aldrich) as described previously (Lye et al., 2010b).

\section{Scanning Electron Microscopy}

The morphology of cells prior and after treatment was observed using scanning electron microscopy as described previously (Lye et al., 2010a). Cell pellet was fixed with McDowell Trump fixative and osmium tetroxide (Sigma-Aldrich), before dehydration with a series of ethanol washes $(50,75,95$, and $100 \%$, vol/ vol) and hexamethyldisilazane (Supelco, Bellefonte, PA). The dried cells were then mounted onto a scanning electron microscopy specimen stub, coated with gold in a sputter coater (Polaran, Walford, UK), and examined under a scanning electron microscope (Leo Supra, Oberkochen, Germany).

\section{Statistical Analysis}

Data were analyzed statistically with SPSS software (version 15.0; SPSS Inc., Chicago, IL). Two-way ANOVA was used to evaluate the significant differences between sample means. The statistical level of significance was preset at $\alpha=0.05$. The multiple comparisons of means were assessed by Tukey test. All data presented were mean values of duplicates, obtained from 3 separate runs $(\mathrm{n}=3)$, unless stated otherwise.

\section{RESULTS}

\section{Growth of Lactobacilli Cells After Fermentation}

Generally, electroporation increased $(P<0.05)$ the growth of most lactobacilli cells after fermentation at $37^{\circ} \mathrm{C}$ for $20 \mathrm{~h}$ (Table 1 ). Increasing electric field strength 
Table 2. Removal of cholesterol $(\mu \mathrm{g} / \mathrm{mL})$ by control and electroporated cells after fermentation at $37^{\circ} \mathrm{C}$ for $20 \mathrm{~h}$ and treatment for $3,3.5$, or 4 ms at field strength of $2.5,5.0$, or $7.5 \mathrm{kV} / \mathrm{cm}^{1}$

\begin{tabular}{|c|c|c|c|c|c|c|c|}
\hline $\begin{array}{l}\text { Strain/field } \\
\text { strength }(\mathrm{kV} / \mathrm{cm})\end{array}$ & Control $^{2}$ & \multicolumn{3}{|c|}{ Electroporation time (ms) } & \multicolumn{3}{|c|}{$P$-value ${ }^{3}$} \\
\hline 2.5 & & $17.86 \pm 0.18$ & $26.61 \pm 0.72$ & $32.76 \pm 0.65$ & & & \\
\hline 5.0 & & $25.94 \pm 0.83$ & $34.21 \pm 0.54$ & $40.42 \pm 0.24$ & & & \\
\hline 7.5 & & $40.47 \pm 0.54$ & $60.47 \pm 0.27$ & $45.47 \pm 0.83$ & & & \\
\hline 2.5 & & $20.21 \pm 0.70$ & $24.58 \pm 0.48$ & $28.18 \pm 0.39$ & & & \\
\hline 5.0 & & $33.23 \pm 0.24$ & $36.88 \pm 0.41$ & $36.98 \pm 0.89$ & & & \\
\hline 7.5 & & $37.86 \pm 0.63$ & $41.20 \pm 0.59$ & $46.30 \pm 0.18$ & & & \\
\hline Lactobacillus bulgaricus FTCC 0411 & & & & & $<0.001$ & $<0.001$ & $<0.001$ \\
\hline $\begin{array}{l}2.5 \\
5.0 \\
7.5\end{array}$ & $24.48 \pm 0.48$ & $\begin{array}{l}26.98 \pm 0.50 \\
30.89 \pm 0.79 \\
40.47 \pm 0.17\end{array}$ & $\begin{array}{l}27.92 \pm 0.55 \\
34.79 \pm 0.33 \\
45.16 \pm 0.16\end{array}$ & $\begin{array}{l}33.28 \pm 0.98 \\
39.74 \pm 0.80 \\
54.17 \pm 0.65\end{array}$ & & & \\
\hline Lactobacillus casei BT 1268 & $35.68 \pm 0.65$ & & & & $<0.001$ & $<0.001$ & $<0.001$ \\
\hline $\begin{array}{l}2.5 \\
5.0 \\
7.5\end{array}$ & & $\begin{array}{l}40.36 \pm 0.36 \\
45.52 \pm 0.45 \\
46.20 \pm 0.63\end{array}$ & $\begin{array}{l}46.88 \pm 0.68 \\
52.76 \pm 1.02 \\
55.10 \pm 0.65\end{array}$ & $\begin{array}{l}52.14 \pm 0.70 \\
53.28 \pm 0.95 \\
57.55 \pm 0.63\end{array}$ & & & \\
\hline
\end{tabular}

${ }^{1}$ Results are expressed as means \pm SD of means; values are means of duplicates from 3 separate runs $(n=3)$.

${ }^{2}$ Control $=$ sample without electroporation treatment.

${ }^{3} \mathrm{~A}=$ effect of electric field strength; $\mathrm{T}=$ effect of treatment duration; $\mathrm{A} \times \mathrm{T}=$ interaction between electric field strength and treatment duration.

also significantly $(P<0.05)$ increased cell growth. Most of the cells treated at the highest field strength $(7.5 \mathrm{kV} /$ $\mathrm{cm})$ had greater $(P<0.05)$ growth after fermentation, whereas lesser $(P<0.05)$ growth was observed for cells treated at $2.5 \mathrm{kV} / \mathrm{cm}$. The growth of $L$. acidophilus FTCC 0291 was increased by 2.5 to $11.7 \%$ upon treatment at $7.5 \mathrm{kV} / \mathrm{cm}$, but showed an increase of only 2.1 to $3.7 \%$ in growth for cells treated at $2.5 \mathrm{kV} / \mathrm{cm}$ compared with the control $(P<0.05)$. In addition, increasing the duration of treatment increased $(P<0.05)$ cell growth, with greater growth following treatment for $4 \mathrm{~ms}$ compared with the other durations studied. This was most prevalent for L. casei BT 1268, where growth increased by only $2 \%$ when cells were treated at $7.5 \mathrm{kV} / \mathrm{cm}$ for $3.5 \mathrm{~ms}$, but showed an increase of $7.1 \%$ upon treatment for $4 \mathrm{~ms}(P<0.05)$.

\section{Assimilation of Cholesterol}

The assimilation of cholesterol by lactobacilli cells was significantly increased $(P<0.05)$ upon electroporation (Table 2) and increased with increasing electric field strength. Cells treated at a field strength of $7.5 \mathrm{kV} /$ $\mathrm{cm}$ showed greater cholesterol assimilation (range from
37.92 to $60.47 \mu \mathrm{g} / \mathrm{mL}$ ) compared with that observed when cells were treated at $2.5 \mathrm{kV} / \mathrm{cm}$ (from 17.86 to $52.14 \mu \mathrm{g} / \mathrm{mL} ; P<0.05)$. A significant increase $(P<$ $0.05)$ in cholesterol removal upon treatment was also observed when cells were treated for a longer duration, except in strains L. acidophilus BT 1088 and L. bulgaricus FTDC 1311, which showed a decrease in cholesterol removal upon treatment for $4 \mathrm{~ms}$ at the highest field strength $(P<0.05)$.

\section{Membrane Permeability}

All lactobacilli cells showed an increase $(P<0.05)$ in membrane permeability upon electroporation (Table 3). Among all field strengths studied, treatment at 2.5 $\mathrm{kV} / \mathrm{cm}$ showed a lesser $(P<0.05)$ effect in promoting cell permeabilization. Meanwhile, a greater $(P<0.05)$ effect in promoting cell permeabilization was observed when cells were treated at a higher field strength of 7.5 $\mathrm{kV} / \mathrm{cm}$. This was most prevalent for L. casei BT 1268, where an increase of $92.0 \%$ was observed when cells were treated at $2.5 \mathrm{kV} / \mathrm{cm}$ for $3 \mathrm{~ms}$ but an increase of $247.9 \%$ upon treatment at $7.5 \mathrm{kV} / \mathrm{cm}$. However, $L$. bulgaricus FTDC 1311 showed a different response, in 
Table 3. Membrane permeability $(\%)$ of control and electroporated cells immediately after electroporation treatment for $3,3.5$, or 4 ms at field strength of $2.5,5.0$, or $7.5 \mathrm{kV} / \mathrm{cm}^{1}$

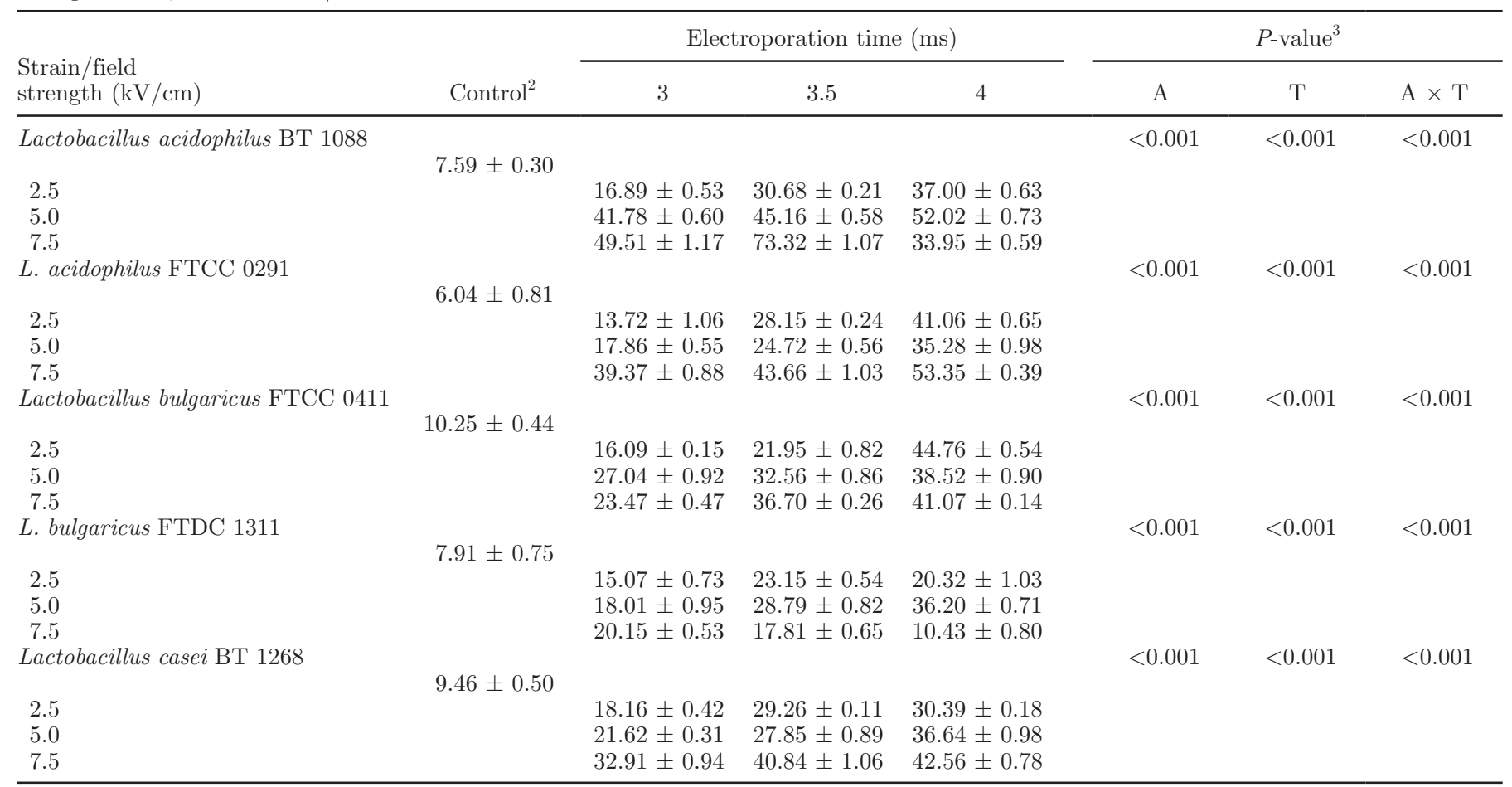

${ }^{1}$ Results are expressed as means $\pm \mathrm{SD}$ of means; values are means of duplicates from 3 separate runs $(\mathrm{n}=3)$.

${ }^{2}$ Control $=$ sample without electroporation treatment.

${ }^{3} \mathrm{~A}=$ effect of electric field strength; $\mathrm{T}=$ effect of treatment duration; $\mathrm{A} \times \mathrm{T}=$ interaction between electric field strength and treatment duration.

which a greater $(P<0.05)$ membrane permeability effect was observed when cells were treated at $5.0 \mathrm{kV} /$ $\mathrm{cm}$. Increasing the duration of treatment also significantly $(P<0.05)$ increased the membrane permeability of cells, except for L. acidophilus BT 1088 and $L$. bulgaricus FTDC 1311, which showed a decrease $(P<$ $0.05)$ in membrane permeability upon treatment at a higher field strength and longer treatment time (7.5 $\mathrm{kV} / \mathrm{cm}$ for $4 \mathrm{~ms}$ ).

\section{Lipid Peroxidation}

The release of malondialdehyde (MDA) by lactobacilli increased significantly $(P<0.05)$ upon electroporation (Table 4). Most of the cells treated at $5.0 \mathrm{kV} / \mathrm{cm}$ showed greater $(P<0.05)$ production of MDA, whereas cells treated at $2.5 \mathrm{kV} / \mathrm{cm}$ showed lesser $(P<0.05)$ production of MDA. This was most prevalent for $L$. bulgaricus FTDC 1311, with an increase of $80.3 \%$ when cells were treated at $5.0 \mathrm{kV} / \mathrm{cm}$ for $3.5 \mathrm{~ms}$, but a smaller increase in production of MDA (48.4\%) compared with the control with treatment at $2.5 \mathrm{kV} / \mathrm{cm}$. In addition, duration of treatment increased cellular lipid peroxidation, in which the concentration of MDA released by cells treated for $4 \mathrm{~ms}$ was greater $(P<0.05)$ than that released by cells treated for shorter durations, except for L. bulgaricus FTDC 1311, which showed a decrease in MDA upon treatment at $7.5 \mathrm{kV} / \mathrm{cm}$ for $4 \mathrm{~ms}$.

\section{Incorporation of Cholesterol into Cellular Membrane}

Ratio of Cholesterol and Phospholipids. The ratio of C:P in the cellular membrane increased significantly $(P<0.05)$ upon treatment and after fermentation (Table 5). Most cells showed an increase $(P<0.05)$ in membrane $\mathrm{C}: \mathrm{P}$ with increasing field strengths, where a higher ratio was observed when cells were treated at $7.5 \mathrm{kV} / \mathrm{cm}$ and a lower ratio at $2.5 \mathrm{kV} / \mathrm{cm}(P<0.05)$. The ratio of C:P in cellular membrane of lactobacilli cells was also increased $(P<0.05)$ with treatment for a longer treatment duration, except for $L$. bulgaricus FTDC 1311, where an increase of $78.3 \%$ was observed upon treatment at $7.5 \mathrm{kV} / \mathrm{cm}$ for $3 \mathrm{~ms}$ and an increase of only $30.4 \%$ for cells treated for $4 \mathrm{~ms}$ compared with the control $(P<0.05)$.

Fluorescence Anisotropy. Electroporation significantly $(P<0.05)$ contributed to an increase in FAn of DPH (Table 6), TMA-DPH (Table 7), and ANS (Table 8) of the cellular membrane upon fermentation. Greater $(P<0.05)$ increases of FAn for DPH (from 
Table 4. Membrane lipid peroxidation (expressed as concentration of malondialdehyde, $\mathrm{nmol} / \mathrm{mL}$ ) of control and electroporated cells immediately after electroporation treatment for $3,3.5$, or $4 \mathrm{~ms}$ at field strength of $2.5,5.0$, or $7.5 \mathrm{kV} / \mathrm{cm}^{1}$

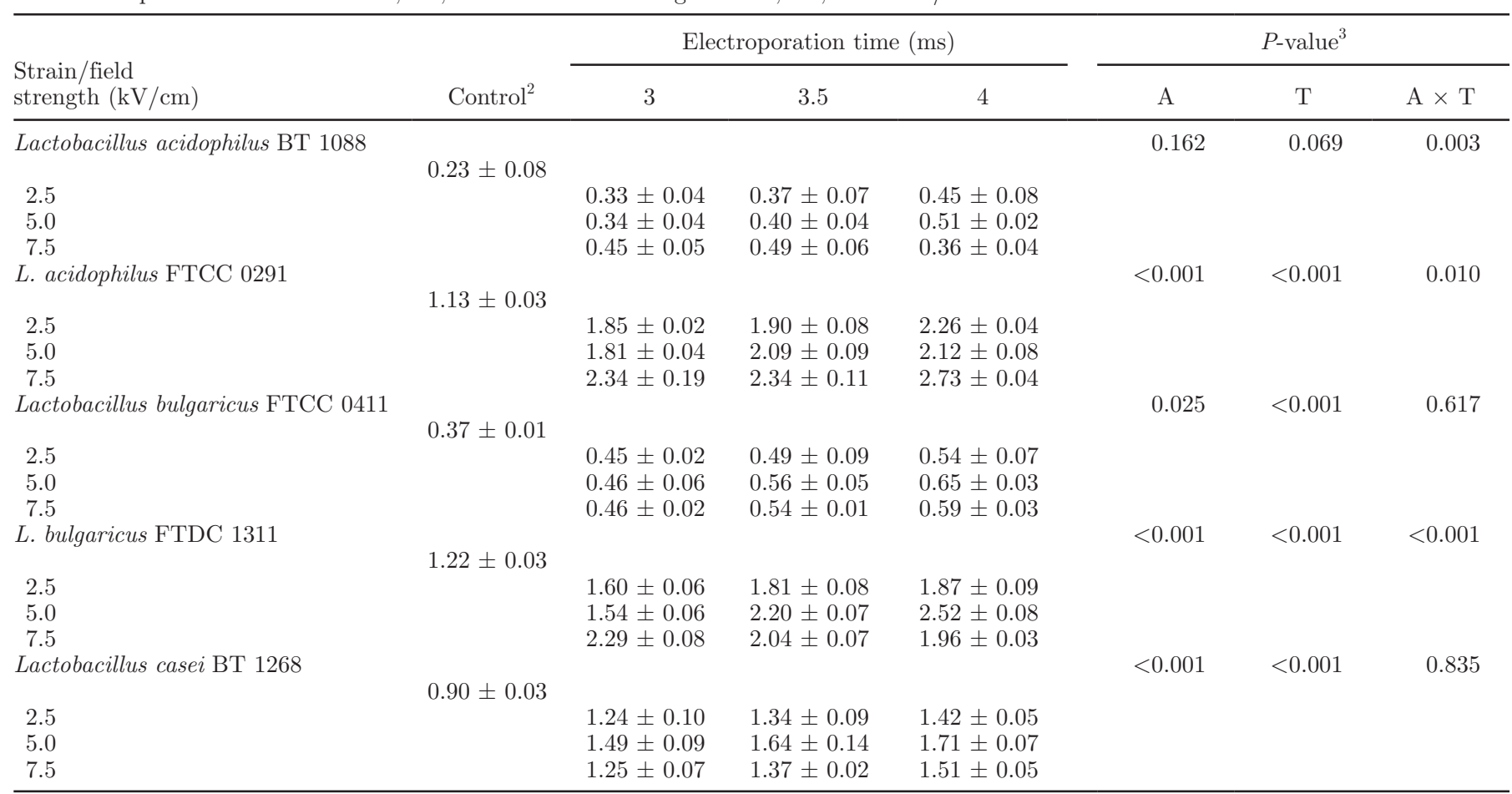

${ }^{1}$ Results are expressed as means \pm SD of means; values are means of duplicates from 3 separate runs $(n=3)$.

${ }^{2}$ Control $=$ sample without electroporation treatment.

${ }^{3} \mathrm{~A}=$ effect of electric field strength; $\mathrm{T}=$ effect of treatment duration; $\mathrm{A} \times \mathrm{T}=$ interaction between electric field strength and treatment duration.

0.32 to 0.94 ), TMA-DPH (from 0.19 to 0.87 ), and ANS (from 0.24 to 0.69 ) were observed upon treatment at $7.5 \mathrm{kV} / \mathrm{cm}$, whereas lesser $(P<0.05)$ increases of FAn for DPH (from 0.26 to 0.86 ), TMA-DPH (from 0.15 to 0.73 ), and ANS (from 0.14 to 0.62 ) were observed for cells treated at $2.5 \mathrm{kV} / \mathrm{cm}$. In addition, the duration of treatment significantly $(P<0.05)$ increased the FAn of DPH, TMA-DPH, and ANS for most lactobacilli cells. However, L. bulgaricus FTDC 1311 showed a different trend, where the increase of treatment duration from 3 to 4 ms showed a decrease $(P<0.05)$ in FAn of DPH, TMA-DPH, and ANS for cells treated at $7.5 \mathrm{kV} / \mathrm{cm}$.

\section{Scanning Electron Microscopy}

Scanning electron microscopy was conducted to examine the effect of electroporation on morphology of lactobacilli cells (Figure 1). Cells without treatment showed a smooth and intact surface (Figure 1A), whereas cells treated with electroporation showed formation of pores and cellular rupturing (Figure 1B).

\section{DISCUSSION}

The alteration of membrane by electroporation is reported to be reversible and transient (Shil et al., 2008).
Our data showed that the growth of electroporated cells was increased after fermentation. The application of electric fields to cells often leads to the accumulation of electrical charges on cellular membranes and subsequent current formation and voltage transmission across the membrane. However, membrane voltage that exceeds a critical value often forms pores that cause structural changes in the surface of membrane, leading to increased membrane permeability (Deng et al., 2003). An increase in membrane permeability might subsequently enhance and facilitate the uptake of nutrient from media. In addition, the death of weaker cells upon treatment may reduce competition for nutrients, leading to higher specific growth rates of surviving cells (Tryfona and Bustard, 2008). The resealing of transient pores upon removal of the electric fields subsequently reversed membrane permeability of cells to their original states (García et al., 2007).

We previously reported that removal of cholesterol was associated with growth (Lye et al., 2010a). Thus, it is essential that lactobacilli cells remain viable in sufficient numbers to assimilate cholesterol. Sublethal strengths of electroporation have been reported not to exert adverse effects on bacterial growth. Less than $1 \log$ reduction was observed when Listeria innocua 
Table 5. Ratio of cholesterol and phospholipids of control and electroporated cells upon fermentation at $37^{\circ} \mathrm{C}$ for $20 \mathrm{~h}$ and electroporation treatment for $3,3.5$, or $4 \mathrm{~ms}$ at field strength of $2.5,5.0$, or $7.5 \mathrm{kV} / \mathrm{cm}^{1}$

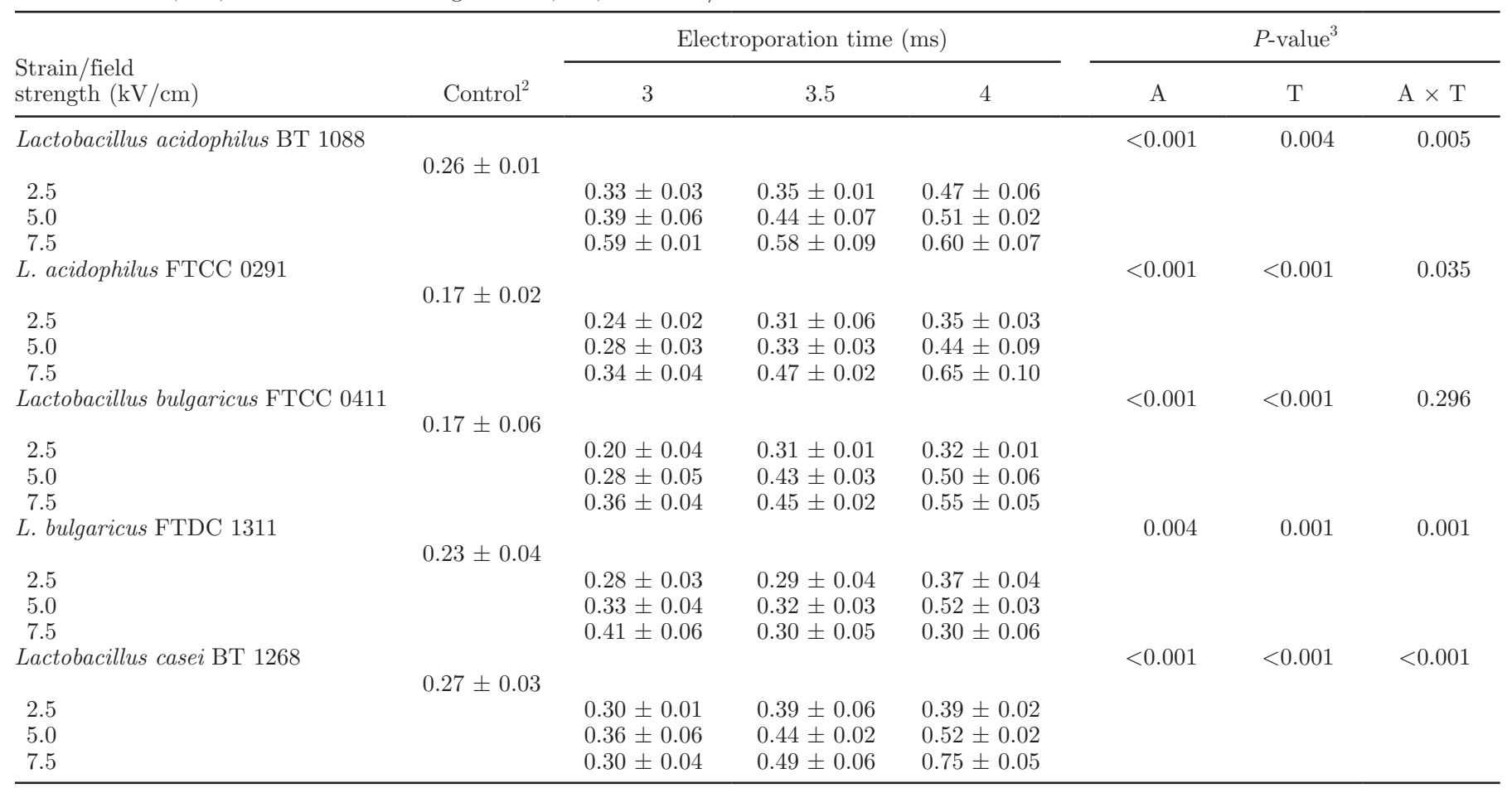

${ }^{1}$ Results are expressed as means \pm SD of means; values are means of duplicates from 3 separate runs $(n=3)$.

${ }^{2}$ Control $=$ sample without electroporation treatment.

${ }^{3} \mathrm{~A}=$ effect of electric field strength; $\mathrm{T}=$ effect of treatment duration; $\mathrm{A} \times \mathrm{T}=$ interaction between electric field strength and treatment duration.

(Aronsson et al., 2005), Escherichia coli, Lactobacillus plantarum, and Salmonella serotype Senftenberg (García et al., 2005) were treated at a field strength of 25 $\mathrm{kV} / \mathrm{cm}$, whereas the same result (less than 1 log reduction) was also observed when Listeria monocytogenes (Fleischman et al., 2004) was treated at $30 \mathrm{kV} / \mathrm{cm}$. Our present data showed that lower field strengths of $2.5,5$, and $7.5 \mathrm{kV} / \mathrm{cm}$ did not exert lethal effects on cellular growth, but instead, promoted growth upon fermentation. Lactobacilli cells often form cellular aggregates and chains (Goh and Klaenhammer, 2010), and electroporation has been found to declump aggregates (Bringel and Hubert, 1990). Thus, we believe that the increased growth of lactobacilli cells after treatment may be attributed to the detachment of clumped cells.

The removal of cholesterol by electroporated cells was increased after fermentation, which may be attributed to the formation of pores upon electroporation that increased membrane permeability to cholesterol. Permeabilized cells often facilitate the uptake or entry of substances from media (García et al., 2007), including cholesterol molecules. As seen in our scanning electron micrographs, pores were formed on the cellular membrane, leading to increased membrane permeability, in tandem with the increased uptake and assimilation of cholesterol. Electroporated cells are promising candidates for incorporation into dairy products to develop new functional dairy foods with a cholesterol-lowering effect.

We further evaluated the membrane properties of electroporated lactobacilli cells. The membranes of cells were permeabilized upon electroporation, as illustrated by the increase in membrane lipid peroxidation. Lipid peroxidation is known to occur upon breakdown of the membrane dielectric potential. Compression of pressure formed due to attraction of opposite charges induced on the inner and outer surfaces of the cell membrane often causes disruption in the membrane bilayer (Park et al., 2003). Local membrane alterations might also be caused by highly reactive free radicals produced from the high temperature and pressure created during treatment (Wu and Nyborg, 2008). These free radicals are able to attack unsaturated lipids of the cellular membrane, inducing membrane lipid peroxidation and cellular damage (Tang et al., 2008).

It was previously found that a critical electrical potential was induced across cell membrane upon application of electric fields, leading to rapid electrical 
Table 6. Fluorescence anisotropy [with 1,6-diphenyl-1,3,5-hexatriene (DPH) as fluorescent probe] of control and electroporated cells upon fermentation at $37^{\circ} \mathrm{C}$ for $20 \mathrm{~h}$ and electroporation treatment for $3,3.5$, or $4 \mathrm{~ms}$ at field strength of $2.5,5.0$, or $7.5 \mathrm{kV} / \mathrm{cm}^{1}$

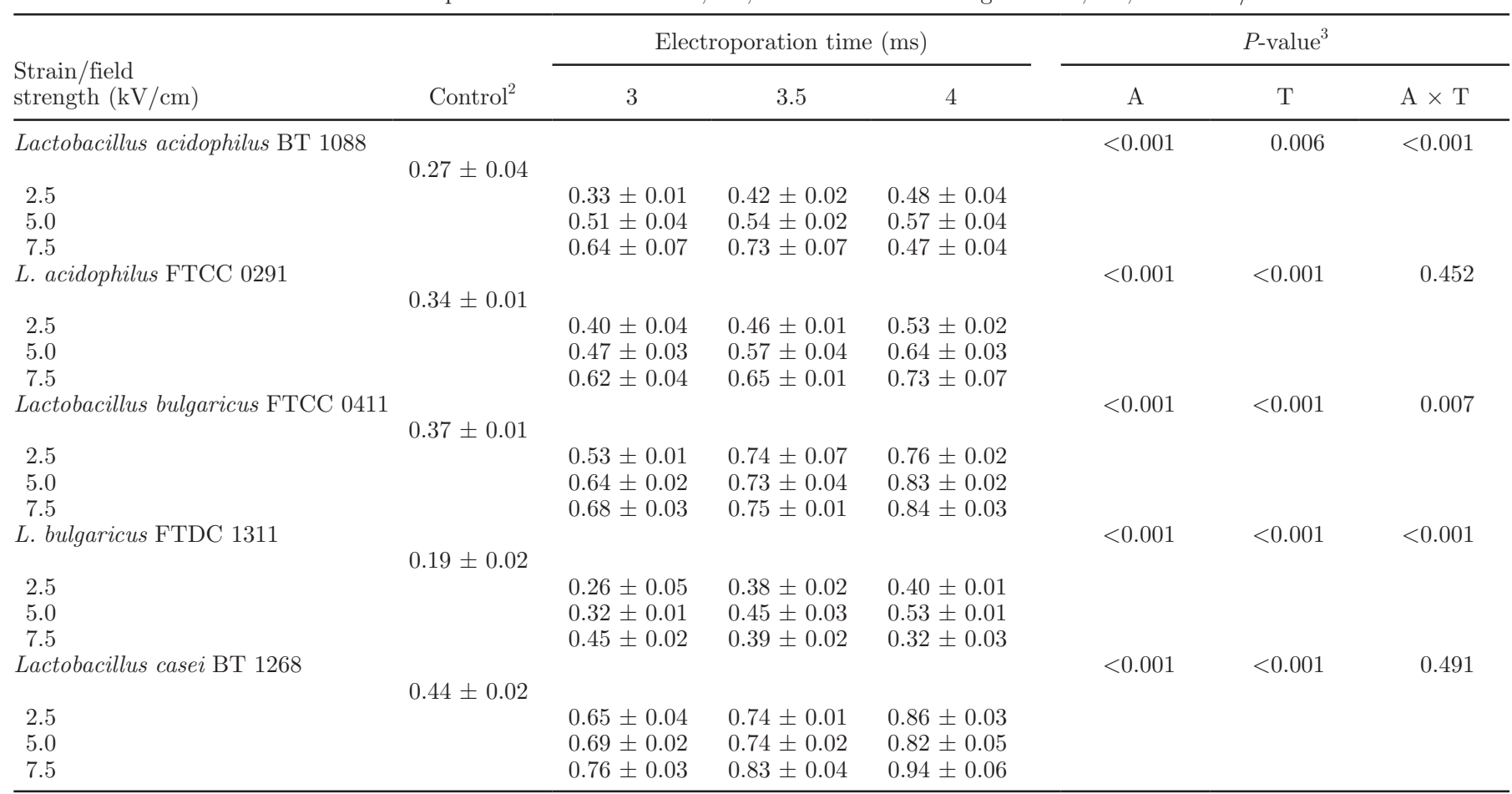

${ }^{1}$ Results are expressed as means \pm SD of means; values are means of duplicates from 3 separate runs $(n=3)$.

${ }^{2}$ Control $=$ sample without electroporation treatment.

${ }^{3} \mathrm{~A}=$ effect of electric field strength; $\mathrm{T}=$ effect of treatment duration; $\mathrm{A} \times \mathrm{T}=$ interaction between electric field strength and treatment duration.

breakdown and local structural changes of the cellular membrane and subsequent lipid peroxidation (Knorr et al., 2001). Peroxidation of membrane lipids has also been reported to result in deterioration of phospholipids composition and subsequent increase in the ratio of cholesterol and phospholipids (Tang et al., 2008). Considering that the cellular membrane lipid bilayer primarily comprises phospholipids and cholesterol, we hypothesized that increased lipid peroxidation induced by electroporation would also alter the ratio of cellular C:P. Our results showed that, after fermentation, the ratio of $\mathrm{C}: \mathrm{P}$ in cellular membrane of most cells was increased by electroporation with increasing field strengths and treatment durations, indicating a possible decrease of membrane phospholipid content.

We previously reported that lactobacilli removed cholesterol via incorporation into the cellular membrane, which led to an increased ratio of C:P in the membrane (Lye et al., 2010b). Most gram-positive bacteria are surrounded by a thick peptidoglycan cell wall (Darnell et al., 1986). However, cell walls normally impede the entry of substrates into the cellular system by the presence of a coarse meshwork (Chen, 2007). These substances can enter and leave the cells via passive processes of diffusion or via carrier proteins (Darnell et al., 1986). Nevertheless, the organization of the cellular membrane is changed upon electroporation because of the transient increase in the transmembrane potential difference. This subsequently increased the membrane permeability to molecules (Galindo et al., 2008). JeanLouis et al. (2006) reported that cellular membrane alteration led to an increased amount of cholesterol in the cellular membrane, attributed to changes in membrane permeability through pore formation, which allowed free access of cholesterol to binding sites on the cytoplasmic side and subsequently increased incorporation of cholesterol into the cellular membrane. An increased cellular cholesterol content has also been reported to increase the ratio of cellular C:P (Moore et al., 2005). In the current study, electroporated cells had a higher ratio of C:P compared with untreated cells, indicating increased incorporation of cholesterol into the cellular membrane.

We further assessed the possible locations of the incorporated cholesterol within the cellular membrane upon electroporation, by using different fluorescence probes such as DPH, TMA-DPH, and ANS. The fluorescence probe DPH is a lipophilic fluorophore that is 
Table 7. Fluorescence anisotropy [with 1-(4-trimethylammonium)-6-phenyl-1,3,5-hexatriene (TMA-DPH) as fluorescent probe] of control and electroporated cells upon fermentation at $37^{\circ} \mathrm{C}$ for $20 \mathrm{~h}$ and electroporation treatment for $3,3.5$, or 4 ms at field strength of $2.5,5.0$, or $7.5 \mathrm{kV} /$ $\mathrm{cm}^{1}$

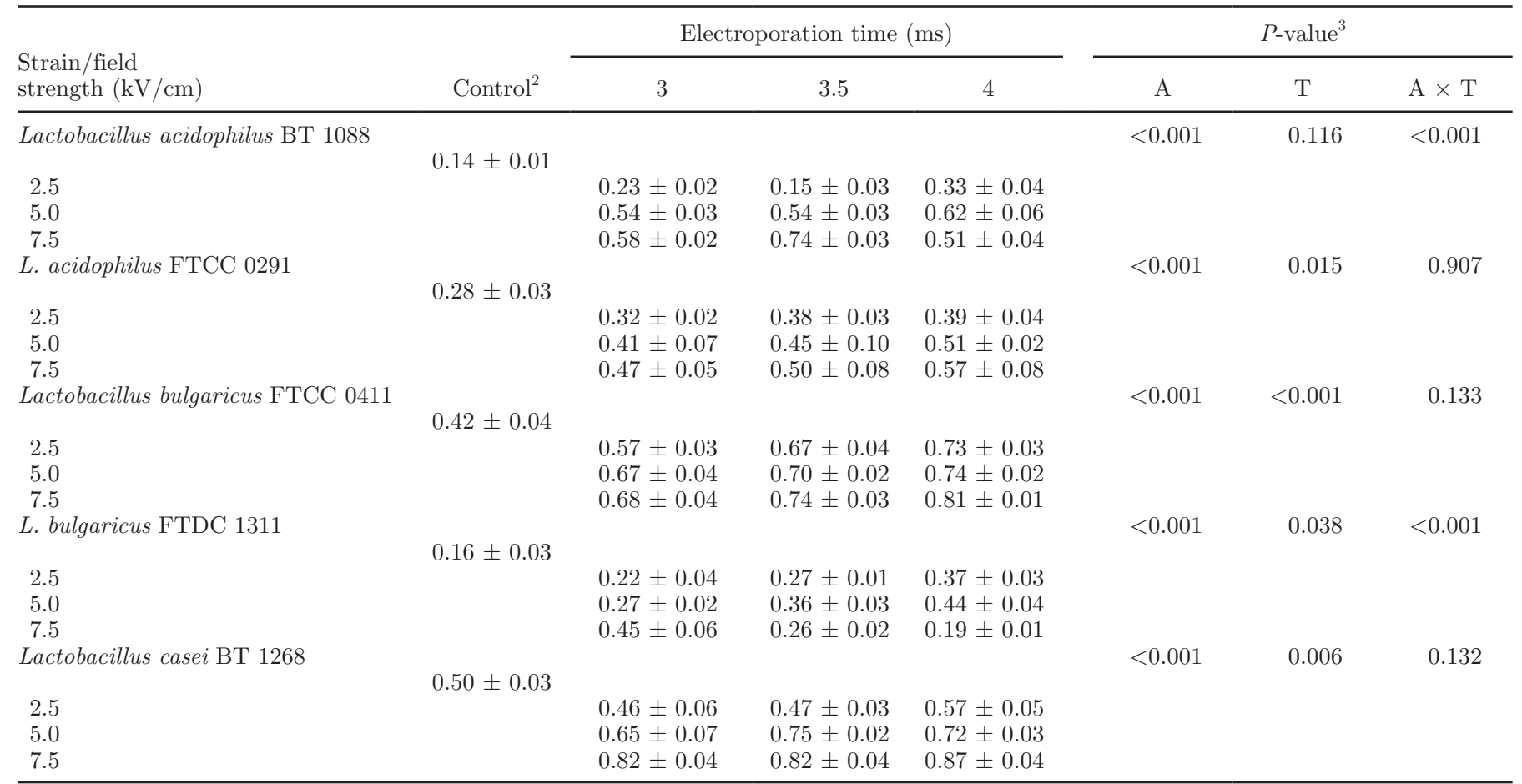

${ }^{1}$ Results are expressed as means \pm SD of means; values are means of duplicates from 3 separate runs $(\mathrm{n}=3)$.

${ }^{2} \mathrm{Control}=$ sample without electroporation treatment.

${ }^{3} \mathrm{~A}=$ effect of electric field strength; $\mathrm{T}=$ effect of treatment duration; $\mathrm{A} \times \mathrm{T}=$ interaction between electric field strength and treatment duration.

mainly incorporated into hydrophobic regions of the membrane. Probe TMA-DPH is a cationic probe with a polar head group, which ensures its parallel alignment to lipid acyl chains. The binding of ANS, an anionic probe, occurs at the interface between the hydrophobic tail and hydrophilic head of phospholipids (Lye et al., $2010 b)$. Electroporation significantly $(P<0.05)$ increased the FAn of DPH, TMA-DPH, and ANS of the cellular membrane upon fermentation, indicating that enrichment of cholesterol was apparent in apolar regions of the membrane, polar regions of the phospholipids and upper regions of the acyl chain, and at the interface between the apolar and polar regions of the phospholipids. Under applied electric fields, the lipid molecules are reorienting and creating hydrophilic pores that impair the bilayer's ability to act as permeability barriers against molecules. Then, the local heating caused by electroporation causes changes in conformation of lipid molecules and rearrangement of the membrane bilayer, which expands the existing hydrophobic pores or forms new ones (Tsong, 1991). The formation of hydrophobic pores subsequently increases the binding of cholesterol to hydrophobic regions of the phospholipids.
In addition, when the cells were permeabilized, the repulsive hydration forces between cells are reduced, promoting fusion of electropulsed membranes (Meaking et al., 1995). This fusion process allows the diffusion of molecules via merging of the outer monolayer of the lipid membrane bilayer without combining the cytoplasmic content (Tsong, 1991). Therefore, cholesterol molecules are free to cross the membrane bilayer and can be incorporated in the hydrophilic regions of phospholipids and the interface between the hydrophobic and hydrophilic regions of the phospholipids. Electroporation can also enhance the inversion of phospholipids that are able to transfer molecules through the inner and outer layers of cell membranes (Teissie et al., 2005) by inducing binding of hydrogen bonds (cholesterol molecules) with the hydrogen-accepting groups of the phospholipid's polar head of the membranes (Ziarno, 2007). This increases incorporation of cholesterol in the polar head regions of phospholipids. In addition, transition of hydrophobic pores into hydrophilic pores has been reported to occur upon electroporation (Teissie et al., 2005), leading to transfers of cholesterol from the apolar tail regions of phospholipids to the polar head regions of phospho- 


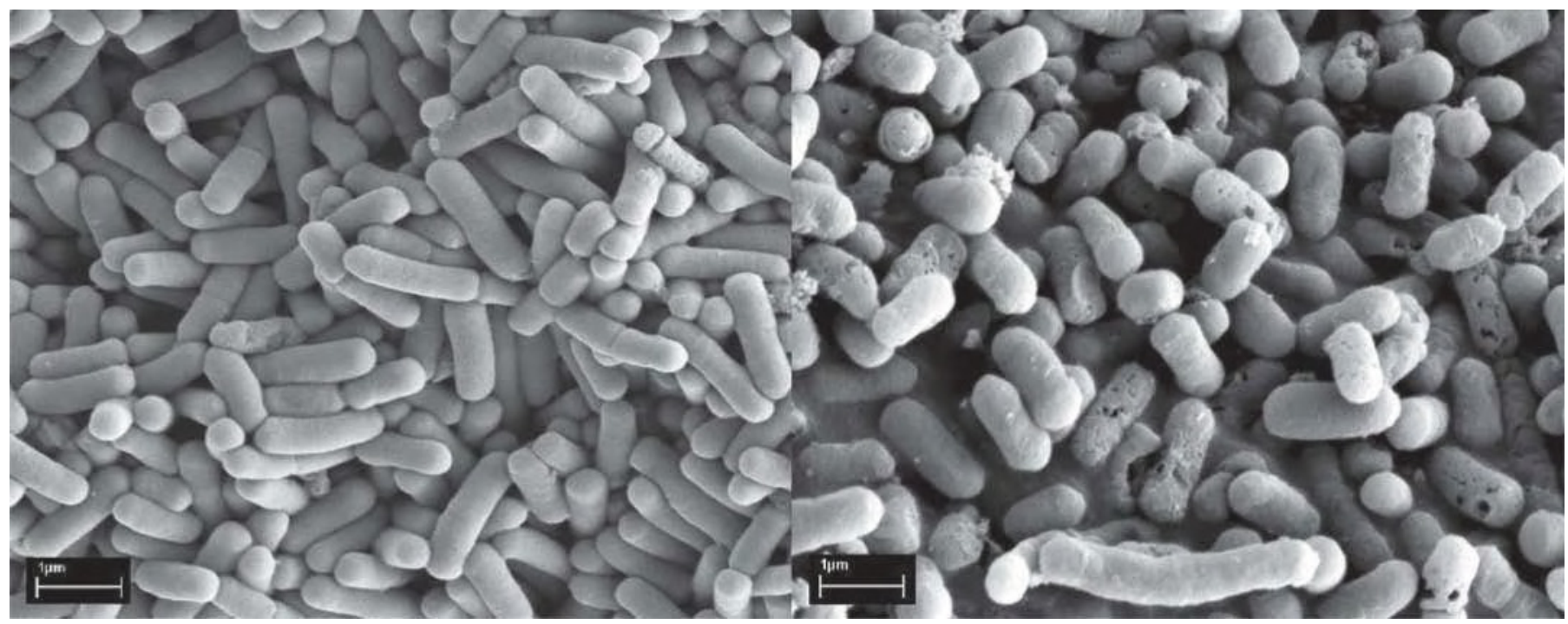

Figure 1. Scanning electron micrographs of (left) lactobacilli cells without treatment and (right) lactobacilli cells treated with electroporation at field strength of $7.5 \mathrm{kV} / \mathrm{cm}$ for $3.5 \mathrm{~ms}$.

lipids. We believe this may have increased the saturation of cholesterol in the regions of hydrophilic head of phospholipids and upper regions of the acyl chain of electroporated cells upon treatment.

\section{CONCLUSIONS}

Electroporation caused changes in the cellular membrane through pore formation, which was reversible

Table 8. Fluorescence anisotropy [with 8-anilino-1-napthalenesulfonic acid (ANS) as fluorescent probe] of control and electroporated cells upon fermentation at $37^{\circ} \mathrm{C}$ for $20 \mathrm{~h}$ and electroporation treatment for $3,3.5$, or $4 \mathrm{~ms}$ at field strength of $2.5,5.0$, or $7.5 \mathrm{kV} / \mathrm{cm}^{1}$

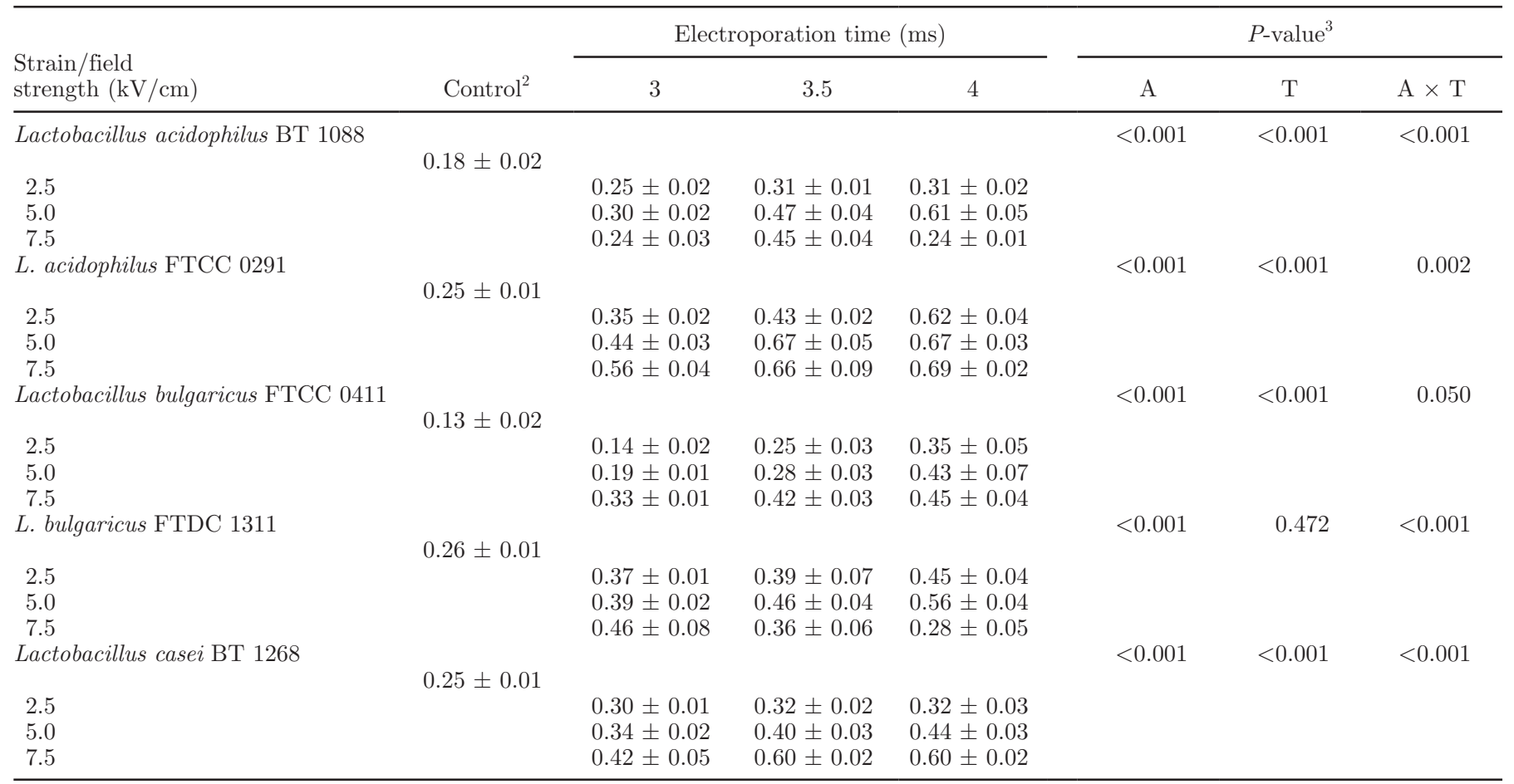

${ }^{1}$ Results are expressed as means \pm SD of means; values are means of duplicates from 3 separate runs $(\mathrm{n}=3)$.

${ }^{2}$ Control $=$ sample without electroporation treatment.

${ }^{3} \mathrm{~A}=$ effect of electric field strength; $\mathrm{T}=$ effect of treatment duration; $\mathrm{A} \times \mathrm{T}=$ interaction between electric field strength and treatment duration. 
and transient in nature, and where electroporated cells showed higher growth than the control upon fermentation. Electroporation also induced lipid peroxidation in the cellular membrane and increased membrane permeability and cholesterol uptake from the medium. This treatment also increased the incorporation of cholesterol into the cellular membrane, accompanied by increased ratio of cellular C:P and saturation of cholesterol in different regions of the membrane bilayer.

\section{ACKNOWLEDGMENTS}

This work was supported by the RU grant (1001/ PTEKIND/811089) and the USM Fellowship (1001/441/CIPS/AUPE001) provided by Universiti Sains Malaysia (Penang).

\section{REFERENCES}

Aronsson, K., U. Ronner, and E. Borch. 2005. Inactivation of Escherichia coli, Listeria innocua and Saccharomyces cerevisiae in relation to membrane permeabilization and subsequent leakage of intracellular compounds due to pulsed electric field processing. Int. J. Food. Microbiol. 99:19-32.

Bringel, F., and J.-C. Hubert. 1990. Optimized transformation by electroporation of Lactobacillus plantarum strains with plasmid vectors. Appl. Microbiol. Biotechnol. 33:664-670.

Chen, R. R. 2007. Permeability issues in whole-cell bioprocesses and cellular membrane engineering. Appl. Microbiol. Biotechnol. 74:730-738.

Darnell, J., H. Lodish, and D. Baltimore. 1986. Molecular Cell Biology. Scientific American Books Inc., New York, NY.

Deng, J. D., K. H. Schoenbach, E. S. Buescher, P. S. Hair, P. M. Fox, and S. J. Beebe. 2003. The effects of intense submicrosecond electrical pulses on cells. Biophys. J. 84:2709-2714.

Fleischman, G. J., S. Ravishankar, and V. M. Balasubramaniam. 2004 The inactivation of Listeria monocytogenes by pulsed electric field (PEF) treatment in a static chamber. Food Microbiol. 21:91-95.

Galindo, F. G., P. T. Vernier, P. Dejmek, A. Vicente, and M. A. Gundersen. 2008. Pulsed electric field reduces the permeability of potato cell wall. Bioelectromagnetics 29:296-301.

García, D., N. Gomez, P. Manas, J. Raso, and R. Pagan. 2007. Pulsed electric fields cause bacterial envelopes permeabilization depending on the treatment intensity, the treatment medium $\mathrm{pH}$ and the microorganism investigated. Int. J. Food Microbiol. 113:219-227.

García, D., N. Gomez, J. Raso, and R. Pagan. 2005. Bacterial resistance after pulsed electric fields depending on the treatment medium pH. Innov. Food Sci. Emerg. Technol. 6:388-395.

Giamarellos-Bourboulis, E. J., S. Skiathitis, A. Dionyssiou-Asteriou, S. Hatziantoniou, K. Demetzos, I. Dontas, G. T. Papaioannou, G. Karatzaz, and G. Helen. 2003. Lipid peroxidation by Pseudomonas aeruginosa in the pathogenesis of nosocomial sepsis. J. Postgrad. Med. 49:11-16.

Goh, Y. J., and T. R. Klaenhammer. 2010. Functional roles of aggregation promoting like factor in stress tolerance and adherence of Lactobacillus acidophilus NCFM. Appl. Environ. Microbiol. 76:5005-5012

Gomes, A. M. P., and F. X. Malcata. 1999. Bifidobacterium spp. and Lactobacillus acidophilus: Biological, biochemical, technological and therapeutical properties relevant for use as probiotics. Trends Food Sci. Technol. 10:139-157.
Holzapfel, W. H., P. Haberer, R. Geisen, J. Bjorkroth, and U. Schillinger. 2001. Taxonomy and important features of probiotic microorganisms in food and nutrition. Am. J. Clin. Nutr. 73:365S$373 \mathrm{~S}$.

Jean-Louis, S., S. Akare, M. A. Ali, E. A. Mash, E. Meuillet, and J. D. Martinez. 2006. Deoxycholic acid induces intracellular signaling through membrane. J. Biol. Chem. 281:14948-14960.

Knorr, D., A. Angersbach, M. N. Eshtiaghi, V. Heinz, and D. Lee. 2001. Processing concepts based on high intensity electric field pulses. Trends Food Sci. Technol. 12:129-135.

Liong, M. T. 2007. Probiotics: A critical review of their potential role as antihypertensives, immune modulators, hypocholesterolemics, and perimenopausal treatments. Nutr. Rev. 65:316-328.

Liong, M. T., and N. P. Shah. 2005. Acid and bile tolerance and the cholesterol removal ability of lactobacilli strains. J. Dairy Sci 88:55-66.

Lye, H. S., C. Y. Kuan, J. A. Ewe, W. Y. Fung, and M. T. Liong. 2009. The improvement of hypertension by probiotics: Effects on cholesterol, diabetes, rennin, and phytoestrogens. Int. J. Mol. Sci. 10:3755-3775.

Lye, H. S., G. Rusul, and M. T. Liong. 2010a. Mechanisms of cholesterol removal by lactobacilli under conditions that mimic the human gastrointestinal tract. Int. Dairy J. 20:169-175.

Lye, H. S., G. Rusul, and M. T. Liong. 2010b. Removal of cholesterol by lactobacilli via incorporation and conversion to coprostanol. J. Dairy Sci. 93:1383-1392.

Meaking, W. S., J. Edgerton, C. W. Wharton, and R. A. Meldrum. 1995. Electroporation induced damage in mammalian cell DNA. Biochim. Biophys. Acta 1264:357-362.

Moore, A. I., E. L. Squires, and J. K. Graham. 2005. Adding cholesterol to the stallion sperm plasma membrane improves cryosurvival. Cryobiology 51:241-249.

Ooi, L. G., R. Bhat, A. Rosma, K. H. Yuen, and M. T. Liong. 2010. A symbiotic containing Lactobacillus gasseri CHO-220 and inulin improves irregularity of red blood cells. J. Dairy Sci. 93:4535-4544. doi:10.3168/jds.2010-3330.

Park, J.-C., M. S. Lee, D. H. Lee, B. J. Park, D.-W. Han, M. Uzawa, and K. Takatori. 2003. Inactivation of bacteria in seawater by lowamperage electric current. Appl. Environ. Microbiol. 69:24052408.

Puc, M., T. Kotnik, L. M. Mir, and D. Miklavcic. 2003. Quantitative model of small molecules uptake after in vitro cell electropermeabilization. Bioelectrochemistry 60:1-10.

Shil, P., S. Bidaye, and P. B. Vidyasagar. 2008. Analyzing the effects of surface distribution of pores in cell electroporation for a cell membrane containing cholesterol. J. Phys. D Appl. Phys. 41:1-7.

Tang, W., Q. Liu, X. Wang, N. Mi, P. Wang, and J. Zhang. 2008 Membrane fluidity altering and enzyme inactivating in sarcoma 180 cells post the exposure to sonoactivated hematoporphyrin in vitro. Ultrasonics 48:66-73.

Teissie, J., M. Golzio, and M. P. Rols. 2005. Mechanisms of cell membrane electropermeabilization: A minireview of our present (lack of?) knowledge. Biochim. Biophys. Acta 1724:270-280.

Tryfona. T., and M. T. Bustard. 2008. Impact of pulsed electric fields on Corynebacterium glutamicum cell membrane permeabilization. J. Biosci. Bioeng. 105:375-382.

Tsong, T. Y. 1991. Electroporation of cell membranes. Biophys. J. 60:297-306.

Wu, J., and W. L. Nyborg. 2008. Ultrasound, cavitation bubbles and their interaction with cells. Adv. Drug Deliv. Rev. 60:1103-1116.

Ziarno, M. 2007. The influence of cholesterol and biomass concentration on the uptake of cholesterol by Lactobacillus from MRS broth. Acta Sci. Pol. Technol. Aliment. 6:29-40.

Ziarno, M. 2008. In vitro cholesterol uptake by Lactobacillus acidophilus isolates. Acta Sci. Pol. Technol. Aliment. 7:65-74. 